\title{
Ovarian transposition and metachronous ovarian metastasis in a premenopausal colorectal carcinoma patient: a case report
}

\author{
Shari Bodofsky ${ }^{1}$, Sean Hong ${ }^{1}$, George N. Botros $^{1}$, Evita Sadimin $^{2} \wedge$, Patrick M. Boland ${ }^{3}$, Matthew P. Deek ${ }^{1} \wedge$ \\ ${ }^{1}$ Department of Radiation Oncology, Rutgers Cancer Institute of New Jersey, Rutgers University, New Brunswick, NJ, USA; ${ }^{2}$ Department of \\ Pathology and Laboratory Medicine, Rutgers Cancer Institute of New Jersey, Rutgers University, New Brunswick, NJ, USA; ${ }^{3}$ Department of \\ Medical Oncology, Rutgers Cancer Institute of New Jersey, Rutgers University, New Brunswick, NJ, USA \\ Correspondence to: Shari Bodofsky. Department of Radiation Oncology, Rutgers Cancer Institute of New Jersey, Rutgers University, 195 Little Albany \\ Street, New Brunswick, NJ 08903, USA. Email: sb1566@rwjms.rutgers.edu.
}

\begin{abstract}
Colon cancer has a high incidence of metastasis, with an estimated $0.8-7.4 \%$ of colorectal adenocarcinoma (CRC) cases metastasizing to the ovary. The role of prophylactic bilateral oophorectomy in CRC is contested in the literature, particularly in premenopausal patients. Further, it is unclear if prophylactic removal of the contralateral ovary is indicated in cases of direct involvement of one ovary to reduce recurrence. Facing a lack of evidence for survival benefit, hormonal complications, and sterilization, some choose to pursue fertility sparing options. For female patients interested in additional pregnancies, the ovaries can be surgically relocated in a prophylactic procedure known as ovarian transposition; as even small doses of radiation to the ovary can effectively sterilize women in their $30 \mathrm{~s}$. We present a case of a 29-year-old female who underwent ovarian transposition of the right ovary before initiating chemoradiation for primary left sided colon adenocarcinoma with direct invasion of the left ovary. Months later, she presented to the emergency department (ED) with abdominal pain suspicious for ovarian torsion. On restaging computerized tomography (CT), she was diagnosed with symptomatic right ovarian metastasis in the transposed ovary, requiring reoperation and oophorectomy. For this patient, and for others facing critical decisions about ovarian preservation in advanced colorectal cancer, the question remains how to balance fertility concerns with optimal minimization of metastasis and recurrence.
\end{abstract}

Keywords: Ovarian transposition; prophylactic oophorectomy; ovarian metastasis; case report

Submitted Sep 08, 2021. Accepted for publication Nov 03, 2021.

doi: 10.21037/jgo-21-558

View this article at: https://dx.doi.org/10.21037/jgo-21-558

\section{Introduction}

Colon cancer has a high incidence of metastasis, with $20 \%$ of patients presenting with Stage IV disease at diagnosis (1). Common sites of metastasis include the lymph nodes, liver, lungs, and peritoneum. An estimated 0.8-7.4\% of colorectal adenocarcinoma (CRC) cases metastasize to the ovary, with even higher rates discovered postmortem at $5-9.7 \%$ (2). Additionally, an estimated $43-70 \%$ of ovarian metastases are bilateral (3). Metastases to the ovary are associated with aggressive disease and poor outcomes (4). For young women with colon cancer, available treatment options often impact fertility. Even small doses of radiation to the ovary can effectively sterilize premenopausal women, with estimates of just 14.3 Gy inducing complete ovarian failure, and radiation tolerances for the ovary limited to just 2 Gy (5). Ovarian transposition is a surgical approach to limit ovarian radiation exposure and preserve fertility. However, it is contested whether ovarian preservation in

^ ORCID: Shari Bodofsky, 0000-0002-5583-7612; Evita Sadimin, 0000-0003-4275-1358; Matthew P. Deek, 0000-0002-5949-5058. 
reproductive age women with colon cancer is advantageous or presents a significant risk for disease recurrence and subsequent morbidity and mortality.

We present a case report of a young female with locally advanced colon cancer who underwent transposition of the contralateral ovary and subsequently experienced metachronous metastasis post chemoradiation and a discussion of the role of ovarian preservation versus prophylactic bilateral oophorectomy. Our case is unique in addressing a premenopausal patient with fertility concerns, for whom the consequences of unnecessary oophorectomy, or of undertreated malignancy, are particularly devastating. We present the following case in accordance with the CARE reporting checklist (available at https://dx.doi. org/10.21037/jgo-21-558).

\section{Case presentation}

A 29-year-old female with past medical history of hydronephrosis and insertion of left ureteral stent for nephrolithiasis presented with large bowel obstruction. Flexible sigmoidoscopy revealed a partially obstructing tumor in the sigmoid colon with adenomatous glandular epithelium and high-grade dysplasia. A $5 \mathrm{~mm}$ right lower lung nodule was found on computerized tomography (CT) scan of the chest, but otherwise no evidence of metastatic disease was present in scans of the abdomen or pelvis. At the time of her hospitalization, her level of carcinoembryonic antigen (CEA) was elevated at $24.1 \mathrm{ng} / \mathrm{mL}$ and both cancer antigens $19-9$ and 125 were within normal limits.

She subsequently underwent upfront low anterior resection in addition to ureterolysis and left salpingooophorectomy due to direct extension of the tumor into the left ureter. Pathology revealed invasive adenocarcinoma of the sigmoid colon, with 3 positive lymph nodes, and negative resection margins resulting in stage pT4bN1b disease. Adjuvant 5-FU, oxaliplatin, and leucovorin (FOLFOX) chemotherapy was administered for 10 cycles. Five months postoperatively, her CEA level had decreased to $1.1 \mathrm{ng} / \mathrm{mL}$. At this time, additional chemoradiation was recommended to improve local control and prevent recurrence. Due to fertility concerns, the gravida 2, para 1 patient underwent interval transposition of the right ovary into the right lower quadrant and right salpingectomy. Afterwards, the patient received 3-D conformal radiation therapy to the rectum with parameters of 4,500 cGy in 25 fractions with concurrent $825 \mathrm{mg} / \mathrm{m}^{2}$ capecitabine taken twice daily for 5 days per week.

One month after completion of chemoradiation, and 10 months since initial diagnosis, the patient presented to the emergency department (ED) with abdominal pain, with CT scans showing possible ovarian torsion. Restaging CT scans completed one month after her ED stay revealed an enlarged, cystic right ovary with ovarian torsion excluded by ultrasound (Figure 1). At that time, CEA levels also began to trend upwards, reaching a peak of $68.4 \mathrm{ng} / \mathrm{mL}$ two months after completion of chemoradiation. Diagnostic laparoscopy, at this point 1 year after initial diagnosis of colon cancer, revealed right ovarian metastasis with no evidence of peritoneal metastases. Right oophorectomy successfully cleared the ovarian mass. The ovary measured $8.0 \times 6.5 \times 6.3 \mathrm{~cm}^{3}$ and weighed 240 grams. Tumor replaced almost the entire ovarian parenchyma and grossly appeared multicystic, with friable to solid, tan-white to tan-yellow, nodules occupying the majority of the cystic spaces. On histology, the tumor was entirely composed of large glands with garland-like pattern, extensive luminal necrosis and occasional calcifications, consistent with metastatic adenocarcinoma from colonic origin (Figure 2). A panel of immunohistochemistry further supports the diagnosis.

All procedures performed in studies involving human participants were in accordance with the ethical standards of the institutional and/or national research committee(s) and with the Helsinki Declaration (as revised in 2013). Written informed consent was obtained from the patient for publication of this case report and accompanying images. A copy of the written consent is available for review by the editorial office of this journal.

\section{Discussion}

We present a case of a 29-year-old female who underwent ovarian transposition of the right ovary as a fertility sparing measure before initiating radiation for primary left-sided colon adenocarcinoma. Months later, she was diagnosed with a right ovarian metastasis requiring right oophorectomy. For this patient, and for others facing critical decisions about ovarian preservation in advanced colorectal cancer, the question remains how to balance fertility concerns with optimal minimization of metastasis and recurrence (Table 1). There is no clear consensus on when ovarian preservation is permissible, especially in the 

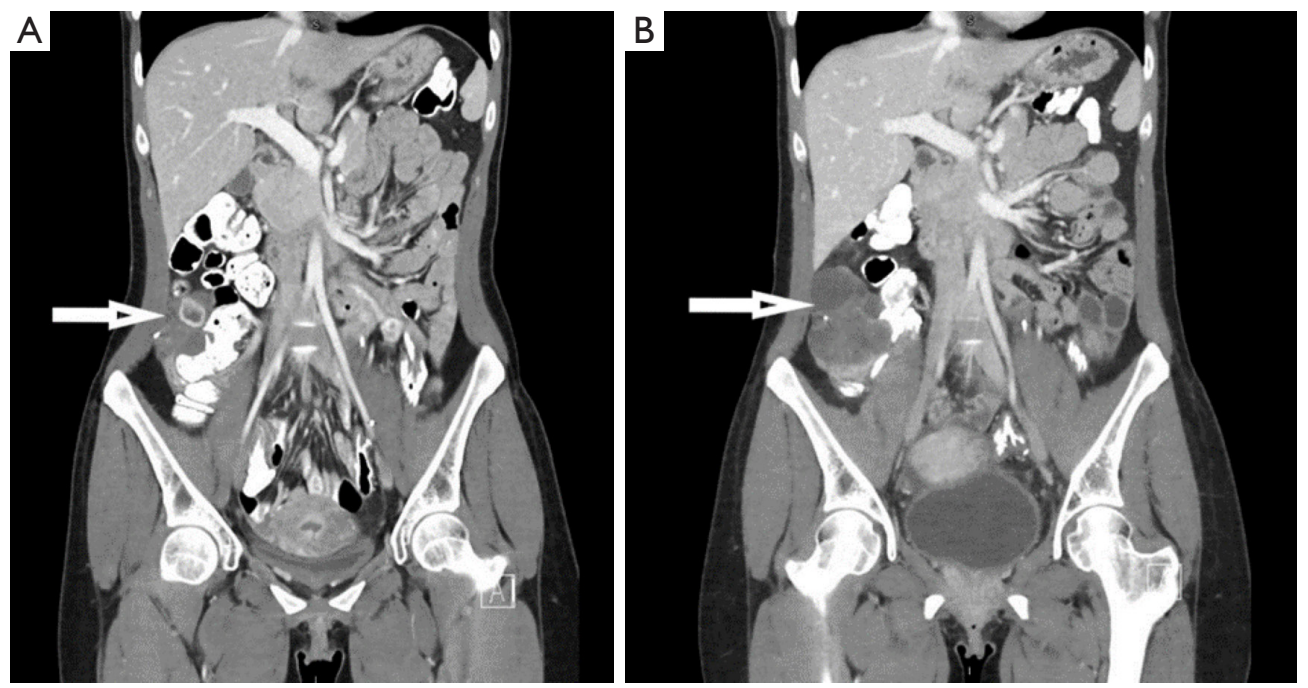

Figure 1 Metastatic progression in the transposed ovary of a 29-year-old female with colorectal adenocarcinoma primary. CT scans of the abdomen and pelvis, 2 months progression. (A) Status post left oophorectomy, post interval transposition of the right ovary into the right lower quadrant with adjacent surgical clips. The ovary is situated between the anterior abdominal wall and the ascending colon. The right ovary appears enlarged, measuring $5.2 \times 2.5 \mathrm{~cm}^{2}$, previously normal in size. (B) The right ovary is enlarged, measuring $7.9 \times 3.9 \mathrm{~cm}^{2}$, and contains multiple cysts. Differential included ovarian torsion and metastasis. Subsequent oophorectomy and pathological analysis confirmed metastasis. CT, computerized tomography.
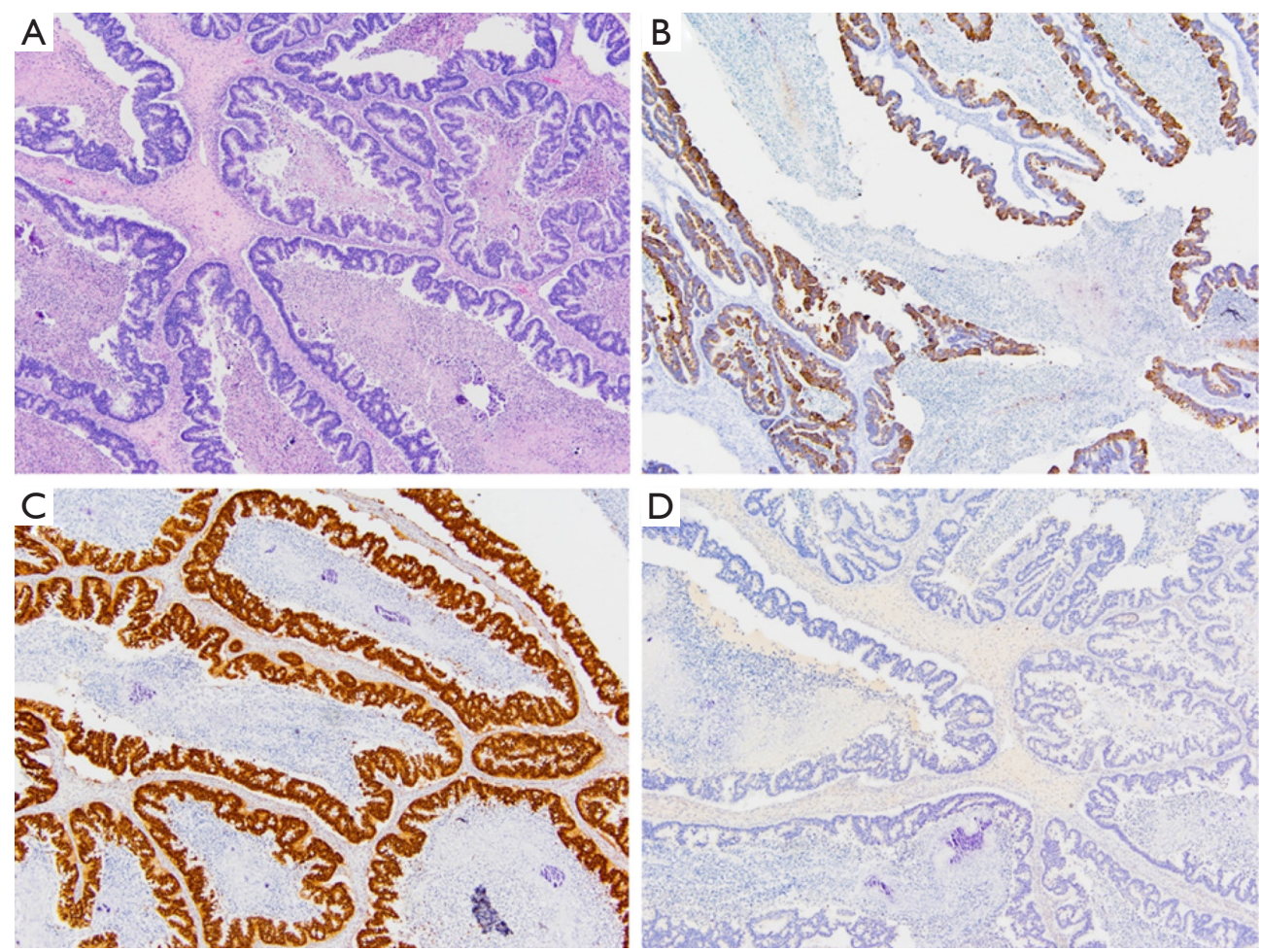

Figure 2 Tumor Histology in a 29-year-old female with metachronous ovarian metastasis. Pictomicrographs of an ovarian tumor in a 29-yearold female with metachronous metastasis after undergoing low anterior resection, left oophorectomy, and right ovarian transposition for colon adenocarcinoma. The tumor is composed of large glands with extensive necrosis and occasional calcifications (A). By immunohistochemistry, it is positive for CK20 (B), CDX2 (C), while negative for PAX8 (D) and CK7 (not shown). All images are shown under 40× magnifications. 
Table 1 Support for ovarian preservation via transposition versus prophylactic oophorectomy in premenopausal colorectal cancer patients

\begin{tabular}{lc}
\hline Ovarian preservation & Prophylactic oophorectomy \\
\hline $\begin{array}{l}\text { Equal survival outcomes } \\
\text { Increased overall survival has not been demonstrated in } \\
\text { premenopausal patients with CRC who underwent prophylactic } \\
\text { oophorectomy }\end{array}$ & $\begin{array}{l}\text { Addresses microscopic disease } \\
\text { If peritoneal involvement is present and one ovary presents with } \\
\text { metastases, there is a 45\% chance the remaining ovary harbors } \\
\text { microscopic disease (6) }\end{array}$ \\
$\begin{array}{l}\text { Avoids hormonal complications } \\
\text { Eliminates high incidence of recurrence in remaining ovary } \\
\text { bone loss, and neurological complications; may require hormone } \\
\text { replacement therapy (7) }\end{array}$ & $\begin{array}{l}\text { If only the affected ovary is removed at initial surgery, } 4 \text { out } \\
\text { Prevents sterilization recurred in the remaining ovary (4) }\end{array}$ \\
$\begin{array}{l}\text { Patients avoid sterilization and expensive fertility interventions (egg } \\
\text { donors, IVF) if future pregnancies are desired }\end{array}$ & $\begin{array}{l}\text { Declining status may prohibit additional operations when } \\
\text { recurrence is discovered (8) }\end{array}$ \\
$\begin{array}{l}\text { Minimizes psychological impact } \\
\text { Allows patients to focus on CRC management and associated } \\
\text { treatment and lifestyle changes, avoids additional sense of loss }\end{array}$ & $\begin{array}{l}\text { Avoids involvement in new anatomic regions } \\
\text { By relocating the ovary into a new anatomic location, previously } \\
\text { uninged structures face heightened risk of involvement should } \\
\text { recurrence develop in the transposed ovary }\end{array}$
\end{tabular}

premenopausal population.

Review of the available literature has shown metastasis to the ovary is present in $0.8-7.4 \%$ of colorectal cancer cases (2). The route of spread from the large bowel to the ovary is not definitively known, but may include transcoelomic spread, hematogenous metastasis, lymphatic spread, and direct extension (Figure 3). While our patient presented with direct tumor extension into the left ovary at initial surgery, it is less clear the mode of metastasis responsible for the metachronous metastasis to the right ovary. As summarized in Hanna and Cohen, metachronous metastasis to the ovary is uncommon, occurring in $1.4-6.8 \%$ of colorectal cancer cases, and usually occurs within 2 years of primary resection (2). Ovarian metastasis is more common in premenopausal patients, which may be associated with their stronger vascular supply, creating a "sanctuary" for metastasis.

For patients like ours, who initially present with synchronous ipsilateral metastasis, the question of how to best address the contralateral ovary remains. Retrospective data in patients with CRC with peritoneal involvement suggests that if one ovary is involved, there is a $45 \%$ chance that the second ovary will have microscopic involvement (6).
However, it is unclear whether this data can be extrapolated to our patient, who did not exhibit peritoneal involvement. In one study, of the five patients who presented with synchronous ovarian metastasis and underwent removal of only the affected ovary, four experienced recurrences in the remaining ovary (4). Additional case reports have pointed to the seriousness of metastasis to the remaining ovary, highlighting that the patient's condition may not permit additional operations (8). Morbidity and mortality are greatly increased for patients with ovarian metastasis compared to those without, with a median survival of just 20 months (9). For this reason, there is considerable interest in preventing ovarian metastasis when feasible.

While initially it may seem that prophylactic bilateral oophorectomy would be advisable, there is considerably disagreement regarding its role, particularly in premenopausal patients. Notably, increased overall survival due to prophylactic bilateral oophorectomy has only been demonstrated in postmenopausal women (10,11). Proposed advantages include potential removal of microscopic synchronous metastases, reduction of metachronous metastases, and eliminating the need for repeated or emergent operation (2). No conclusions have been drawn 


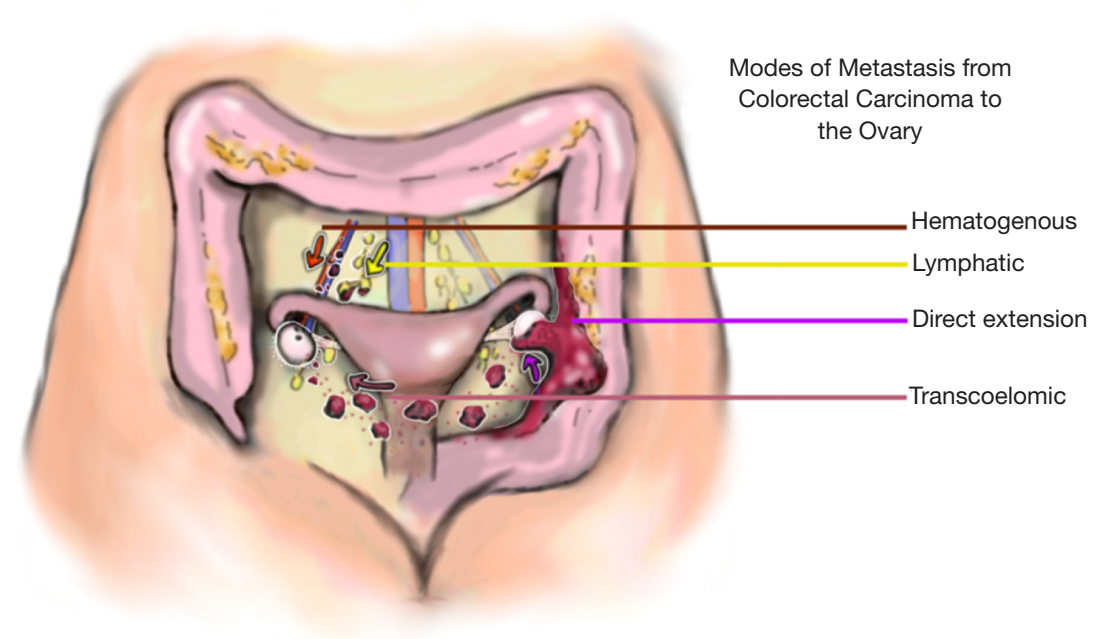

Figure 3 Modes of metastasis from colorectal carcinoma to the ovary. Illustration of the modes of metastasis from colorectal carcinoma to the ovary. Proposed modes of metastasis include hematogenous spread via the blood, lymphatic spread via the pelvic lymph nodes, direct extension from the primary tumor into the adjacent ovary, and transcoelomic spread across the peritoneal cavity.

on its benefit in premenopausal patients. However, bilateral prophylactic oophorectomy comes with risk of significant morbidity and potential development of cardiac, bone, and neurological complications if patients do not receive estrogen replacement therapy (7). Oophorectomy may also cause significant psychological stress and necessitate invasive and expensive fertility treatment.

Thus, the use of prophylactic bilateral oophorectomy in premenopausal women requires careful and individualized consideration. Facing a lack of evidence for survival benefit, hormonal complications, and sterilization, some choose not to pursue prophylactic oophorectomy. However, their fertility concerns often extend to the medical and radiation therapies used to control their primary malignancy. Radiation therapy can effectively sterilize women in their $30 \mathrm{~s}$, with estimates of 14.3 Gy inducing ovarian failure and the threshold for ovarian preservation is limited at just 2 Gy (5). These patients may undergo ovarian transposition, a surgical procedure to relocate the ovary while maintaining its native blood supply, removing it from the radiation field, and preserving reproductive potential. For patients such as ours, with involvement at one ovary, and the intention of future pregnancies, the decision to undergo ovarian transposition of the remaining ovary is largely dictated by personal choice, as little data instructs an obvious clinical decision. However, our patient now faces disruptive clinical symptoms and reoperation as well as the risk of reducing survival outcomes. There is additional concern that transposition of an ovary harboring microscopic disease may effectively spread the disease to new sites in the abdomen or peritoneum.

While it is difficult to make any firm conclusions on the treatment of similar cases, it is important to note the growing body of case reports pointing to metastasis and poor outcomes in patients who chose not to undergo prophylactic bilateral oophorectomy (Table 2). Our case addresses a premenopausal patient with fertility concerns, for whom the consequences of unnecessary oophorectomy, or of undertreated malignancy, are particularly devastating. The case is unique in presenting recurrence in a transposed ovary. Providing informed, scientifically guided medical advice to such patients will depend on future studies investigating the outcomes of prophylactic surgical intervention before chemoradiation. 
Table 2 Case reports of metastasis to the ovary postoperatively in colorectal adenocarcinoma

\begin{tabular}{|c|c|c|c|c|}
\hline Preoperative diagnosis & Primary operation & Menstruation status & Outcome & Reference \\
\hline Rectal carcinoma & Anterior resection & Premenopausal & $\begin{array}{l}\text { Right ovarian metastasis at } 16 \text { months, } \\
\text { left ovarian metastasis at } 31 \text { months, } \\
\text { death at } 36 \text { months }\end{array}$ & $(8)$ \\
\hline $\begin{array}{l}\text { T3N1M0 colon } \\
\text { adenocarcinoma }\end{array}$ & Right hemicolectomy & Premenopausal & $\begin{array}{l}\text { Bilateral ovarian metastasis at } \\
23 \text { months }\end{array}$ & (13) \\
\hline $\begin{array}{l}\text { Carcinoma of descending } \\
\text { colon and simultaneous } \\
\text { hepatic metastasis }\end{array}$ & $\begin{array}{l}\text { left hemicolectomy and } \\
\text { hepatectomy }\end{array}$ & Postmenopausal & $\begin{array}{l}\text { Ovarian metastasis at } 1 \text { year post } \\
\text { chemotherapy }\end{array}$ & $(16)$ \\
\hline Ascending colon carcinoma & Right hemicolectomy & Postmenopausal & $\begin{array}{l}\text { Right ovarian metastasis at } 7 \text { months, } \\
\text { left ovarian metastasis at } 58 \text { months }\end{array}$ & (8) \\
\hline $\begin{array}{l}\text { T3NOMO adenocarcinoma of } \\
\text { sigmoid colon }\end{array}$ & Left hemicolectomy & Postmenopausal & Right ovarian metastasis at 3 years & $(17)$ \\
\hline
\end{tabular}

Case reports identified via PubMed search in August 2021, keywords "colorectal metastasis to ovary", "recurrence ovarian transposition" and "metachronous ovarian metastasis" with case report filter, selected for relevance.

\section{Acknowledgments}

Funding: None.

\section{Footnote}

Reporting Checklist: The authors have completed the CARE checklist. Available at https://dx.doi.org/10.21037/ jgo-21-558

Conflicts of Interest: All authors have completed the ICMJE uniform disclosure form (available at https://dx.doi. org/10.21037/jgo-21-558). The authors have no conflicts of interest to declare.

Ethical Statement: The authors are accountable for all aspects of the work in ensuring that questions related to the accuracy or integrity of any part of the work are appropriately investigated and resolved. All procedures performed in studies involving human participants were in accordance with the ethical standards of the institutional and/or national research committee(s) and with the Helsinki Declaration (as revised in 2013). Written informed consent was obtained from the patient for publication of this case report and accompanying images. A copy of the written consent is available for review by the editorial office of this journal.

Open Access Statement: This is an Open Access article distributed in accordance with the Creative Commons Attribution-NonCommercial-NoDerivs 4.0 International License (CC BY-NC-ND 4.0), which permits the noncommercial replication and distribution of the article with the strict proviso that no changes or edits are made and the original work is properly cited (including links to both the formal publication through the relevant DOI and the license). See: https://creativecommons.org/licenses/by-nc-nd/4.0/. 


\section{References}

1. Siegel RL, Miller KD, Jemal A. Cancer statistics, 2016. CA Cancer J Clin 2016;66:7-30.

2. Hanna NN, Cohen AM. Ovarian neoplasms in patients with colorectal cancer: understanding the role of prophylactic oophorectomy. Clin Colorectal Cancer 2004;3:215-22.

3. Herrera-Ornelas L, Mittelman A. Results of synchronous surgical removal of primary colorectal adenocarcinoma and ovarian metastases. Oncology 1984;41:96-100.

4. Kammar PS, Engineer R, Patil PS, et al. Ovarian Metastases of Colorectal Origin: Treatment Patterns and Factors Affecting Outcomes. Indian J Surg Oncol 2017;8:519-26.

5. Wallace WH, Thomson AB, Saran F, et al. Predicting age of ovarian failure after radiation to a field that includes the ovaries. Int J Radiat Oncol Biol Phys 2005;62:738-44.

6. Mehta AM, Bignell MB, Alves S, et al. Risk of Ovarian Involvement in Advanced Colorectal or Appendiceal Tumors Involving the Peritoneum. Dis Colon Rectum 2017;60:691-6.

7. Berek JS, Chalas E, Edelson M, et al. Prophylactic and risk-reducing bilateral salpingo-oophorectomy: recommendations based on risk of ovarian cancer. Obstet Gynecol 2010;116:733-43.

8. Yamaguchi T, Takahashi H, Kagawa R, et al. The role of prophylactic bilateral oophorectomy at the time of initial diagnosis of a unilateral ovarian metastasis in cases with colorectal adenocarcinoma. Hepatogastroenterology 2008;55:434-7.

9. Rayson D, Bouttell E, Whiston F, et al. Outcome after ovarian/adnexal metastectomy in metastatic colorectal

Cite this article as: Bodofsky S, Hong S, Botros GN, Sadimin E, Boland PM, Deek MP. Ovarian transposition and metachronous ovarian metastasis in a premenopausal colorectal carcinoma patient: a case report. J Gastrointest Oncol 2021;12(6):3141-3147. doi: 10.21037/jgo-21-558 carcinoma. J Surg Oncol 2000;75:186-92.

10. Sianesi M, Bertocchi E, Rossini $M$, et al. Ovarian metastases from colorectal cancer: prognostic role of prophylactic oophorectomy. A single center experience. Eur J Gynaecol Oncol 2016;37:792-5.

11. Young-Fadok TM, Wolff BG, Nivatvongs S, et al. Prophylactic oophorectomy in colorectal carcinoma: preliminary results of a randomized, prospective trial. Dis Colon Rectum 1998;41:277-83; discussion 283-5.

12. Almas T, Ullah M, Kaneez M, et al. Gone but Not Forgotten: Ovarian Metastasis From a Colon Carcinoma in a 19-Year-Old Female. Cureus 2020;12:e9466.

13. Sahai P, Mohanti BK, Raina PK, et al. Colon cancer with metachronous presentation of Krukenberg's tumor in an adolescent. J Gastrointest Cancer 2014;45 Suppl 1:144-7.

14. Takagi T, Nakase Y, Fukumoto K, et al. A patient with metachronous ovarian metastases of signet-ring cell carcinoma of the transverse colon showing longterm survival after surgery. Gan To Kagaku Ryoho 2009;36:2260-2.

15. Shigeyoshi I, Komori K, Kinoshita T, et al. A case of metachronous left ovarian metastasis 8 years after surgery for cecal cancer and right ovarian metastasis: Report of a case. Nagoya J Med Sci 2017;79:259-66.

16. Eto E, Ito $\mathrm{Y}$, Mihara $\mathrm{K}$, et al. A case of metachronous ovarian metastasis after curative surgery of colon cancer with simultaneous hepatic metastasis. Gan To Kagaku Ryoho 2013;40:1927-9.

17. Paramythiotis D, Goulas $\mathrm{P}$, Moysidis M, et al. Metachronous Ovarian Metastases in a Patient with Primary Colorectal Cancer. A Case Report and Review of the Literature. Am J Case Rep 2019;20:1515-20. 